\title{
Essential Concepts for the First Year of Study for BSc Mathematics
}

Alexander Capes, Sheffield Hallam University, Sheffield, United Kingdom. Email:

alex.capes@hotmail.co.uk.

Peter Rowlett, Sheffield Hallam University, Sheffield, United Kingdom. Email: p.rowlett@shu.ac.uk.

\begin{abstract}
To inform discussion about content for the first year of undergraduate mathematics, a study was completed which reviewed: the A-level Mathematics specification; published literature on the transition from A-level to university mathematics; the second and third year curricula of modules at three English universities with different foci. This aimed to investigate what students might reasonably be expected to have covered when they arrive at university, what happens in practice at the transition to university, and the role of the first year as preparation for later study. Content suggestions focus on calculus, linear algebra and analysis as core topics. There is also evidence of the need to focus on students' understanding of where formulae and solutions originated as well as their ability to produce pieces of academic and mathematical writing. Findings also include suggestion that what happens in the first year, while similar between institutions, does depend on the overall focus of the degree programme.
\end{abstract}

Keywords: undergraduate, mathematics education, transition, Further Education, Higher Education.

\section{Introduction}

Although a reasonable amount of research exists regarding issues faced by students transitioning from Further to Higher Education in the field of mathematics, there is little discussion of concepts that are key during the first year of study for a BSc Mathematics course. This article is designed to provide some discussion in this area, through analysis of the Department of Education GCE Mathematics specification (DoE, 2016), review of relevant literature, and examination of BSc Mathematics courses at three UK universities, selected to provide a varied basis for discussion. Readers should note the anglocentricism of this article, as the university courses selected for discussion are based in England, and the Further Education analysis uses only the GCE A-level specification, in lieu of potential alternatives such as the International Baccalaureate.

\section{Method}

The research for this project aimed to examine three key elements that must be considered when discussing BSc Mathematics first year curricula: the material studied directly prior to the first year of study (in the UK, Further Education most commonly takes the form of A-levels); the differences in material, focus, student independence and other factors between further level mathematical education, and higher level; and the curricula at three UK universities, specifically selected for maximum contrast in their focuses on pure and applied topics in mathematics, covering as broad a scope as possible without focusing too heavily on this area.

\subsection{Review of A-level syllabus}

Preliminary research involved an in-depth analysis of the Department for Education specification for A-level Mathematics, to ascertain the level of knowledge that can be assumed of university starters. A-levels are the UK standard qualification of Further Education (typically studied for between the ages of 16 and 19), and the vast majority of BSc Mathematics courses at UK universities require an 
A-level (or equivalent) qualification in Mathematics, ordinarily at grade $\mathrm{C}$ minimum. This analysis formed a basis for the rest of the research undertaken, as it highlighted the areas of mathematics that are studied in depth, and areas that potentially require additional support during the first year of undergraduate study.

\subsection{Literature Review: Issues in Transition from Further to Higher Education}

A literature review covers material from over 50 years of research into the difficulties faced by students of mathematics at the further and higher levels, providing an overview of opinions of some experts in this field. Additionally, some examination of the differences between Further and Higher Education is included to contextualise any comparisons thereof.

\subsection{Review of Second and Third Year Curricula at Three UK Universities}

The third part of this article is a comparison of the second and third year curricula at three UK universities for their respective BSc Mathematics courses, the aim of which is to identify some mathematical topics and skills that are required to be covered in the first year of higher level study as preparation for the second and third years. The QAA Benchmark Statement (QAA, 2015) defines mathematics degrees on a spectrum from "theory-based" to "practice-based" and allows a broad range of options for the focus of a degree. The universities chosen will remain unnamed, and shall be hereon referred to as University A, B and C, respectively. University A is a research-intensive, pre-1992 university, with Mathematics courses ranked in the top five on entry tariff (Guardian League Table, 2018), whose BSc Mathematics course features a strong focus on pure mathematics. University $B$ is a research-intensive, pre-1992 university with Mathematics courses ranked around $20^{\text {th }}$ on entry tariff (Guardian League Table, 2018), whose BSc Mathematics course aims to balance the focus between pure and applied topics. Finally, University C is a post-1992 university with Mathematics courses ranked bottom 10 by entry tariff (Guardian League Table, 2018), whose Mathematics course focuses strongly on applied mathematics.

\section{A-level Syllabus Review}

The A-level syllabus splits the content of the Pure Core modules into ten discrete sections (DfE, 2016), which are as follows: Proof, Algebra and Functions, 2-Dimensional Coordinate Geometry, Sequences and Series, Trigonometry, Exponentials and Logarithms, Differential Calculus, Integral Calculus, Numerical Methods, and Vectors.

In addition to the basic concepts of Proof, the syllabus names proof by exhaustion, deduction, contradiction, and disproof by counterexample, as areas of study to be covered. Although students must learn the principles of these techniques, it could be suggested that more emphasis on rigorous and sound mathematical reasoning when constructing proofs would benefit those students continuing into higher level mathematics.

The Algebra and Functions section of the syllabus aims to build some foundations of algebraic manipulation methods required for further study of calculus and analysis; the syllabus covers a wide breadth of topics, including surds, algebraic manipulation of polynomials and first- and seconddegree inequalities, laws of exponents, proportional relationships, partial fractions, and the manipulation of functions and their graphs.

In Co-ordinate Geometry, students can be expected to study straight-line equations, circular geometry, and parametric equations. These topics provide foundations for work using ordinary and partial differential equations, and general work in areas of analysis, such as measure theory. 
The Sequences and Series section provides essential introductions to concepts such as sums to infinity (used in a wide variety of contexts in analysis), the general idea of infinite series/sequences, and iterative formulae. Additionally, students are introduced to sigma notation, and other classical notation.

The Trigonometry section of the syllabus goes beyond the basics of sines, cosines, and tangents, and covers their reciprocals and inverses, various trigonometric identities, and double angle formulae. Some proofs involving trigonometric functions are also included on the syllabus. This understanding of trigonometry is integral in the study of any topic involving waves, signals, and/or analytical methods.

The main direct precursors to undergraduate level calculus and analysis (and any topics containing differentials and integrals) on the syllabus are the Exponentials and Logarithms, Differential Calculus, and Integral Calculus sections. Students are taught the basics of differentiation and integration, including the chain, product, and quotient rules of differentiation, and integration by parts and substitution. The syllabus also mentions the Fundamental Theorem of Calculus. Linking this knowledge with exponential functions and logarithmic laws gives students the basis to study most higher topics with strong calculus components. Continuing the work on integration, students are introduced to numerical methods of solution for definite integrals (using Simpson's Rule and the Trapezium Rule), widely used in a variety of applied topics at undergraduate level.

Finally, the syllabus covers Vectors in 2- and 3-dimensions; although the syllabus sticks to the basics of vectors (running through vector notation, component and magnitude/direction forms, the geometric implications of position vectors, and basic vector arithmetic), these concepts are imperative for any later study involving the complex plane, and/or vector calculus.

\section{Literature Review: Issues in Transition - Further to Higher}

Questions may be raised about the efficiency and depth of the previously discussed curriculum, when considering the importance of concepts behind proof and calculus (Prendergast et al., 2017), and the changing standards of assessment at A-level. For example, Epstein (2013) notes that assigning work based on derivations of formulae and justifications thereof, rather than algebraic drills, has proven to greatly improve students' understanding of the topic of calculus, and demonstrated benefits for students who have continued into tertiary study. Epstein also notes that while a direct cause-and-effect relationship cannot be established between the assignment of these tasks and an increase in technical prowess - due to the strong positive correlation, further discussion is warranted. By contrast, it is noted that some students view mathematics as a "rote learning activity" (Nardi and Steward, 2003; p. 362); a problem also highlighted in school inspections (Ofsted, 2012).

Lawson (1997) notes that in a study carried out by Coventry University, in which undergraduate students were asked a series of questions based on principles that are covered in the A-level curriculum, the attainment levels of students with $A, B$ and $C$ grades were virtually indistinguishable from one another. This raises the question of whether A-level grades are a worthwhile indicator of students' later ability to study mathematics at higher level.

As noted in Tackling the Mathematics Problem (LMS, IMA and RSS, 1995), issues surrounding Alevel programmes and their efficacy in preparing students for undergraduate study have been of concern for governmental (Burghes, 1990) and non-governmental (Osmon, 2013) organisations since the 1990s. Moore (1994) suggests that the minimal focus on the fluent mathematical writing is detrimental to students' abilities to construct formal proofs, which makes a strong case for the introduction of some measure to remedy this imbalance. Additionally, What Maths do you need for University? (Osmon, 2010) indicates that the absence of linear algebra in the A-level curriculum puts students at a clear disadvantage, given the range of mathematical topics requiring its usage. 
Burton and Haines (1997) suggest that the burden of fixing the issues in transition lies with the designers of the A-level specification, implying that a higher level of contextualisation of techniques would aid students in their general understanding of topics such as calculus and analysis. A strong understanding of differential calculus is noted by Biza et al. (2016) as a vital prerequisite for undergraduate level study of mathematics. Abdulwahed, Jaworski and Crawford (2012) support this, suggesting that earlier introductions of contextualised calculus problems would potentially give students a more meaningful understanding of these subject areas, whilst also granting them greater insight into the sort of mathematics covered at undergraduate level.

Kalajdzievska (2014) showed that students creating their own questions and mark-schemes for areas of calculus demonstrated a lack of understanding of the fundamental reasoning behind the uses of calculus in applied mathematics. This suggests that giving students a greater focus on the applications of calculus at an earlier point in their education would potentially benefit them by the time they reach undergraduate level. Ellis et al. (2015) highlighted the need for a keen understanding of the principles of calculus in first-year undergraduate mathematics study, due to the prominence of calculus throughout BSc Mathematics courses; this lends credence to the notion that calculus must form a substantial element of the first year of any BSc Mathematics course, due to the reliance on it in most further module areas.

Another issue in transition is that of students' lack of technical and mathematical fluency in their exams and written assignments. The results of a study by Stylianou, Blanton and Rotou (2015) into undergraduates' understanding of proof and its surrounding concepts posit that students do understand the importance of proof and well-written mathematical arguments, however they are not encouraged enough through the means of assessment to improve their own mathematical communication skills. Solomon (2006) suggests that a lack of contextualised material at A-level hinders students' understanding of the importance of mathematical communication; for example, due to the lack of a coursework element, students are almost never required to construct long-form mathematical arguments, supported by their own mathematical assertions, as is the case at degree level. It is also suggested in a paper by Hoyles, Newman and Noss (2001) that critical evaluation of mathematics problems is an area of poor understanding for many undergraduate mathematics students, which demonstrates the need for change at some level to address this issue.

lannone and Simpson $(2011,2012)$ have posited that there is a fundamental lack of students' ability to explain their mathematical ideas in an academic manner, which is suggestive of a requirement for more universities to place emphasis on these issues as early as possible in their BSc Mathematics programmes. This assertion is supported by Sofronas et al. (2015), who note that calculus is used as a unifying thread in the first year of undergraduate teaching, and the contextualisation of calculus as a pure mathematical concept is directly beneficial to students in this regard. This ties back into the aforementioned requirement for students' to possess a keen understanding of the applications of pure mathematics and the theories behind calculus and analysis, as noted by Jaworski, Mali and Petropoulou (2017), who state the importance of explaining the reasoning mathematical principles to students.

It should be noted that all of the studies with experimental components mentioned here contained relatively small sample sizes, rendering their validity somewhat questionable in this context. Additionally, due to the inherently subjective nature of topics in pedagogy, there is likely to be confirmation bias present in some of the sources named. In spite of these elements, there is still clearly a strong case for a need for change at some level to address the growing concerns surrounding the transition from A-level study, to degree level study. 


\section{Examination of Selected University Curricula}

As stated previously, part of this study involves an examination of the second- and third-year modules of the BSc Mathematics courses at three UK universities, selected for the different focuses of their courses, in order to provide a strong and clear contrast. In spite of this contrast, it should be clear that there are several common required skills and technical areas of knowledge across the three courses. It should be noted that the sample size has been kept deliberately small, to enable a more thorough examination of each university in the time available for this study.

Firstly, the BSc Mathematics course at University A focuses heavily on pure mathematics, with students expected to carry out rigorous and extensive proofs of a wide variety of subject areas, and utilise both analytical and numerical methods of solution for the real-world contexts, when they are mentioned. More so than with the other mentioned university courses, students of this course must clearly possess a strong level of competence in terms of differential and integral calculus, as well as confidence in proof construction, algebraic discourse, a variety of forms of mathematical notation, and academic writing with a substantial mathematics component as a whole.

The BSc Mathematics course at University B features a more balanced programme in terms of pure and applied mathematics, with students having the option to determine how much they want to lean in either direction; this element of choice is particularly noteworthy in this context, as the university must ensure students are equally capable in a variety of areas during their first year of study, such that they can excel in their second and third years of study in more specialised areas. The majority of modules on this course require a clear understanding of the principles of calculus and analysis, along with a strong focus on producing professional-looking work with a sound basis in fact and mathematical reasoning. There is a slight emphasis on the study of mathematical physics, with one core module in each of the second and third years of study centring around topics in it. In accordance with typical scientific modules at universities, these modules require strong analytical skills, and excellent objective writing abilities, backed up by well-grounded mathematical arguments, presented in a clear, objective manner. Finally, there is also an emphasis on the proper construction of proofs, such that several core modules contain elements of proof construction as either a focus, or a sidebar. These proof-based tasks clearly also require the ability to construct strong, sound mathematical arguments and present them in a way that is professional and clear to the reader.

Finally, the BSc Mathematics course at University $\mathrm{C}$ has a strong focus on applied mathematics over pure mathematics. Nonetheless, students are still required to produce work demonstrating a clear and present understanding of analytical methods of solution, as well as utilising differential, integral and vector calculus in an applied mathematics context - such as in final year modules focused on fluid mechanics and modelling using partial differential equations. Additionally, students are required to produce professional and academically credible pieces of mathematical writing, which clearly necessitates a keen understanding of the principles of mathematical fluency in communication - a common theme throughout all the modules analysed, with the exception of the final year project, which can of course take very different directions on a student-by-student basis.

\section{Discussion}

This article aimed to inform discussion of curriculum developments at first year undergraduate level by examining what students who studied A-level can be expected (in principle) to have covered before they arrive at university, what happens (in practice) at the transition to university and the role of the first year as preparation for later study.

While the A-level syllabus covers a wide range of important material, this investigation suggests that too little emphasis is placed on ensuring that students understand where formulae and solutions 
originated, with too much focus on learning by rote; arguably (e.g. Epstein, 2013) a major cause of students' difficulties in making the transition to university level mathematics from A-level.

The examination of later years of study at three universities highlights the variety of practice in UK higher education mathematics degrees. All three courses clearly meet the standards set out by the QAA Benchmark Statement (QAA, 2015), despite having considerable differences. This invites the suggestion that the first year of a university maths degree should differ according to the nature of the degree course. Despite differences, it is noted that students studying for any of these courses would be required to have strong understanding of calculus, linear algebra and analysis. The evidence examined here also highlights the need to produce pieces of academic and mathematical writing. It may be concluded from this study that these topics are considered key elements of a wide variety of mathematics undergraduate courses. Good (2011) reports on an exercise where representatives of UK mathematics departments were asked to "list the top five topics they felt a mathematics undergraduate must not graduate without knowing". Note that Good's focus is on the whole degree, not just the first year. The most common mathematical choices reported by Good were topics around analysis, calculus and linear algebra, and the exercise reported also highlighted "the ability to communicate mathematics" among other valued graduate attributes. The findings of this present study, then, support those reported by Good.

It should be noted that the study here is based on examination of a small number of university courses and a review of some relevant literature. However, a picture has emerged of measures that could be taken to assist students with the transition to becoming university mathematics students. The evidence reviewed in this study leads to the conclusion that the first year of an undergraduate curriculum could place greater emphasis on creating and communicating clear mathematical arguments. This would aid students with key issues around transition and provide a strong basis for later study.

\section{References}

Abdulwahed, M., Jaworski, B. and Crawford, A., 2012. Innovative approaches to teaching mathematics in higher education: a review and critique. Nordic Studies in Mathematics Education, 17(2), pp. 49-68.

Biza, I., Giraldo, V., Hochmuth, R., Khakbaz, A., Rasmussen, C., 2016. Research on Teaching and Learning Mathematics at the Tertiary Level. http://dx.doi.org/10.1007/978-3-319-41814-8

Burghes, D., 1990. A-level Mathematics: A Time for Change? Teaching Mathematics and its Applications, 9(3), pp. 97-101. http://dx.doi.org/10.1093/teamat/9.3.97

Burton, L., Haines, C., 1997. Innovation in teaching and Assessing Mathematics at University Level. Teaching in Higher Education, 2(3), pp. 273-293.

http://dx.doi.org/10.1080/1356215970020308

Department for Education, 2016. Mathematics AS and A Level Content. London: Department for Education.

Ellis, J., Hanson, K., Nuñez, G., Rasmussen, C., 2015. Beyond Plug and Chug: an Analysis of Calculus I Homework. International Journal of Research in Undergraduate Mathematics Education, 1(2), p. 268-287. http://dx.doi.org/10.1007/s40753-015-0012-z

Epstein, J., 2013. The Calculus Concept Inventory - Measurement of the Effect of Teaching Methodology in Mathematics. Notices of the American Mathematical Society, 60(8), pp. 10181026. http://dx.doi.org/10.1090/noti1033 
Good, C., 2011. 'We can't let them graduate unless...' In: P. Rowlett, ed., 2011. HE Mathematics Curriculum Summit. Birmingham, U.K.: Maths, Stats and OR Network. pp. 15-16.

The Guardian, 2017. Guardian University League Table 2018. [online] Available at:

https://www.theguardian.com/education/ng-interactive/2017/may/16/university-league-tables-2018 [Accessed 15 October 2017].

Hoyles, C., Newman, K., Noss, R., 2001. Changing patterns of transition from school to university mathematics. International Journal of Mathematical Education in Science and Technology, 32(6), pp. 829-845. http://dx.doi.org/10.1080/00207390110067635

lannone, P. and Simpson, A., 2011. The summative assessment diet: how we assess in mathematics degrees. Teaching Mathematics and its Applications, 30(4), pp. 186-196.

http://dx.doi.org/10.1093/teamat/hrr017

lannone, P., Simpson, A., 2012. Oral assessment in mathematics: implementation and outcomes. Teaching Mathematics and its Applications, 31(4), pp. 179-190.

http://dx.doi.org/10.1093/teamat/hrs012

Jaworski, B., Mali, A., Petropoulou, G., 2017. Critical Theorising from Studies of Undergraduate Mathematics Teaching for Students' Meaning Making in Mathematics. International Journal of Research in Undergraduate Mathematics Education, 3(1), pp. 168-197.

http://dx.doi.org/10.1007/s40753-016-0044-z

Kalajdzievska, D., 2014. Taking Math Students From "Blah" to "Aha": What can we do? PRIMUS, 24(5), pp. 375-391. http://dx.doi.org/10.1080/10511970.2014.893937

Lawson, D., 1997. What can we expect from A-level Mathematics Students? Teaching

Mathematics and its Applications, 16(4), pp. 151-156 http://dx.doi.org/10.1093/teamat/16.4.151

London Mathematical Society (LMS), Institute of Mathematics and its Applications (IMA), Royal Statistical Society (RSS), 1995. Tackling the Mathematics Problem. Available at:

http://mei.org.uk/files/pdf/Tackling the Mathematics Problem.pdf [Accessed 15 October 2017].

Moore, R., 1994. Making the transition to formal proof. Educational Studies in Mathematics, 27(3), pp. 249-266. http://dx.doi.org/10.1007/BF01273731

Nardi, E. and Steward, S., 2003. Is Mathematics T.I.R.E.D? A Profile of Quiet Disaffection in the Secondary Mathematics Classroom. British Educational Research Journal, 30(3), pp. 345-367. http://dx.doi.org/10.1080/01411920301852

Ofsted, 2012. Mathematics: made to measure. Messages from inspection evidence (Report No. 110159). Manchester: Office for Standards in Education, Children's Services and Skills.

Osmon, P., 2010. What maths do you need for university? Proceedings of the British Society for Research into Learning Mathematics, 30(2), pp. 41-46. Available at: http://www.bsrlm.org.uk/wpcontent/uploads/2016/02/BSRLM-IP-30-2-08.pdf [Accessed 15 October 2017].

Osmon, P., 2013. A-level mathematics reform: satisfying the requirements of university courses across the range of mathematical subjects. Proceedings of the British Society for Research into Learning Mathematics, 33(1), pp. 43-48. Available at: http://www.bsrlm.org.uk/wpcontent/uploads/2016/02/BSRLM-IP-33-1-08.pdf [Accessed 15 October 2017].

Prendergast, M., Faulkner, F., Breen, C., Carr, M., 2017. Mind the gap: an initial analysis of the transition of a second level curriculum reform to higher education. Teaching Mathematics and its Applications, 36(1), pp. 1-15. http://dx.doi.org/10.1093/teamat/hrw024 
QAA, 2015. Subject Benchmark Statement: Mathematics, Statistics and Operational Research. Available at: http://www.qaa.ac.uk/en/Publications/Documents/SBS-Mathematics-15.pdf [Accessed 15 October 2017].

Sofronas, K., DeFranco, T., Swaminathan, H., Gorgievski, N., Vinsonhaler, C., Wiseman, B., Escolas, S., 2015. A Study of Calculus Instructors' Perceptions of Approximation as a Unifying Thread of the First-Year Calculus. International Journal of Research in Undergraduate Mathematics Education, 1(3), pp. 386-412. http://dx.doi.org/10.1007/s40753-015-0019-5

Solomon, Y., 2006. Deficit or Difference? The Role of Students' epistemologies of Mathematics in their Interactions with Proof. Educational Studies in Mathematics, 61(3), pp.373-393. http://dx.doi.org/10.1007/s10649-006-6927-1

Stylianou, D., Blanton, M., Rotou, O., 2015. Undergraduate Students' Understanding of Proof: Relationships Between Proof Conceptions, Beliefs, and Classroom Experiences with Learning Proof. International Journal of Research in Undergraduate Mathematics Education, 1(4), pp. 91134. http://dx.doi.org/10.1007/s40753-015-0003-0

\section{Acknowledgements}

This work resulted from Alex Capes' undergraduate dissertation, supervised at Sheffield Hallam University by Peter Rowlett. Funding for Alex to adapt his dissertation into this article was provided by an Education Grant from the Institute of Mathematics and its Applications (EG12/2017), for which we are grateful. 